\title{
Is There an Audience in the Lady's Bedchamber? Shakespeare's Dramatic Trope in the Sleep-Walking Scene in Macbeth
}

\section{Manidip Chakraborty}

Assistant Professor, Dept of English, Bhairab Ganguly College, West Bengal State University, India. Mail ID: manidipfalta@gmail.com ORCID ID: 0000-0001-9421-0196

\begin{abstract}
In William Shakespeare's Macbeth, the famous Sleep-Walking scene of Lady Macbeth also includes two observers, the Waiting-Gentlewoman and the Doctor of Physic, who play multiple roles during this scene, as well as in the development of the Lady's character. In their somewhat choric role, they amplify the Lady's utterances, and sway the audience's attitude. In applying the moral yardstick, their brief observation and comments are really significant. Standing inbetween the Lady and the audience, they let the playwright employ his favourite trope of playwithin-the-play. In their crucial roles as interpreters, they also help the critics establish the gendered logocentrism in analysing events and characters.
\end{abstract}

Keywords: Audience, Experience, Metatheatre, Performance, Knowledge

\section{Introduction:}

The very prospect of one or more (preferably male) characters getting to watch a lady sleeping has been used multiple times within the Shakespearean dramatic oeuvre. Oberon and Puck watching over Lady Titania sleeping and waking to fall in love with a random artisan $(A$ Midsummer Night's Dream), Othello secretly watching Desdemona before he kills her (Othello), Octavius Caesar and his whole train having a close look at the body of the seemingly asleep Cleopatra (Antony and Cleopatra) - all these instances bear some clear elements of voyeuristic pleasure. In most cases, as it is, the woman subject to the secret 'watching' either ends up becoming a victim of adultery (in case of Titania), or death/murder (in case of Desdemona and Cleopatra). Lady Macbeth, as one finds in the Act V, Sc-i of Macbeth (Macbeth 270-75), is no exception too. Of course, she is sleep-walking, and not merely sleeping. Still, after being secretly watched by the Waiting-Gentlewoman and the Doctor of Physic (Act V, Sc-i), she is never seen on the stage again, and the report of her apparent suicide (Act V, Sc-v) is delivered to Macbeth later on. The present article seeks to understand why this act of 'watching' on the part of the Waiting- 
Gentlewoman and the Doctor of Physic is so important in determining the fate of the formidable character of Lady Macbeth. A Psychoanalytic approach has been applied to contextualize the dramatic representation of the characters of Lady Macbeth, the Waiting-Gentlewoman and the Doctor of Physic. Also, a Feminist approach has been used to better assess the transformation in the behaviour of Lady Macbeth.

\section{Retrospection:}

Speaking in terms of events that take place on the stage, not much really happens during Act V, Sc-i of Macbeth. (Macbeth 270-75)

With a burning taper in her hand, Lady Macbeth passes from one room to another, muttering strange and apparently incoherent or delirious words (somniloquy) which actually unravel the bottom of her subconscious mind that she so long kept repressed. (Dutta 66)

Structurally, however, the scene is of utmost importance, as the words uttered by Lady Macbeth attain a kaleidoscopic dimension by commenting on various scenes that have already taken place. It enables the audience to have a recapitulation of things that have been taking place during the span of the play which, according to the timeline of the play itself, covers around a decade. What is interesting, though, is the fact that most of these conversations or experiences she is now referring to must have happened when she was accompanied by none other than her husband. In some instances, as it appears, even the 'real' audience seems to have been absent. For example, as she utters the following words: “The Thane of Fife had a wife. Where is she now?" (Macbeth 273) or, "Banquo's buried; he cannot come out on's grave", (Macbeth 274), there seems to be no direct allusion to scenes that took place on the stage. Are these pieces taken out of some secret conversations? Is she merely imagining to have made these conversations? The audience cannot be very sure, but the feeling that some absolutely private moments (real or imaginary) are making their way into the public sphere of collective knowledge is unmistakably felt.

\section{Play within the Play:}

From the 'theatrical' considerations, Lady Macbeth's 'revelations' are currently being recorded by the Doctor of Physic and the Waiting-Gentlewoman who, in some way, are spectators idealized. Their being in the position to watch the 'spectacle' in its entirety has given the dramatist a remarkable scope to employ some innovative dramatic practices, to sway the public opinion regarding the ultimate evaluation/understanding of the character of Lady Macbeth, and to probe deep into the dark corners of human mind to add to the psychological depth of the play. This is part of a metatheatrical enterprise as the playwright seems to make the audience aware of the fact of its being an artistic performance. The spectacle of the 'performing' Lady Macbeth and the role of the two observers who receive from this 'show' what they want, and interpret things how they want - the whole process appears to imitate the way things are done within the space of the 
theatre. The moment the audience gets an understanding of his/her power to determine the course of events in a drama, the trajectory of the play must undergo some rapid changes.

The technique, in some way at least, is similar to the 'Play within the Play' in both $A$ Midsummer Night's Dream (The Tragedy of Pyramus and Thisbe in Act V Sc-i) and Hamlet (The Murder of Gonzago in Act III, Sc-ii) which showcase a group of characters (or, Actors, to be more precise) enacting a performance before another set of characters. The latter group, in each case, keeps making comments on the 'performance' all the while; thus proving its immense importance in interpreting the 'meaning' of the multifaceted performance to the 'actual' audience. In case of $A$ Midsummer Night's Dream, the constant interjections made by the Duke and his company, combined with the amateurish production of the Artisans, in effect turn the intended tragedy into a hilarious comedy. In Hamlet too, it is Prince Hamlet who makes sure that the attempts of the Players have a definitive impact on Claudius, the supposed murderer. In this case, however, the Prince of Denmark gets involved in the process to ensure that the 'theatrical' performance merges with real life (of other characters like Claudius and his mother, and not the 'life' of the real audience). Unlike the Duke Theseus, Hamlet makes no trivializing comment on the enactment; after all, he has this agenda of preparing his tailor-made mouse-trap and catch his uncle off the guard. While Theseus's interjections spoil the mimetic effect, it is the smooth movement of the Prince of Denmark on different levels of understanding that makes the play-within-the-play so life-like.

If we can consider Lady Macbeth's incoherent mutterings as a 'performance' of its own kind, the Doctor of Physic and the Waiting-Gentlewoman perfectly fit into this category of intermediary 'observers' who perform the task of translating, or rather amplifying the speeches of the Lady. The mutterings of Lady Macbeth must possess sufficient pauses, to enable the two observers to register their brief yet pertinent commentaries. Unlike what the Duke Theseus does, the Doctor of Physic and the Waiting-Gentlewoman wait for their cues, and insert their commentaries only when they have the scope to do so. Also, unlike what we have seen in $A$ Midsummer Night's Dream and Hamlet, however, the 'performance' here is not consciously done; nor is it an imitation of an actual act. It is the chaotic expressions of the subconscious, brought into the world of the conscious through the participation and explanation of the two observers. There is no attempt on the part of the two observers to make things appear 'life-like'. On both visual and verbal levels, the spectacle-within-the-spectacle seems to convey to the audience all it intends to.

\section{The Chorus:}

The Doctor of Physic and the Waiting-Gentlewoman in Act V, Scene-i of Macbeth represent the observers whose approval or rejection is absolutely necessary in determining the course of one's career. In that respect, they carry the essence of the classical chorus which usually comprises a group of inconsequential, average human beings. They are average, indeed. But they are not a 'group' in the sense that they are easily distinguishable from each other. Moreover, at least in the dramatic scheme, they are far from being inconsequential. In a way, these two 'minor' characters 
represent the lucid world of the Conscious which experiences the horrifying, chaotic world of dream and reverie. They represent the moral standpoint against which the secret deeds of individuals are to be judged. Although it is difficult to consider them as agents of retribution, they easily bring to the mind the classical Eumenides along with their role as silent observers. Throughout the course of the drama, rumours seem to have a crucial role to play. It is not unfair to assume that these two spectators, when they leave the bedchamber, will divulge what they have just experienced. This might prove to be quite important in shaping popular opinion against the royal couple. These two minor characters, then, might just appear to be essential in bringing about the downfall of the titular character and his formidable lady. It is nothing more than a conjecture; still it is worth noting.

Unlike the Chorus in Oedipus the King, the Waiting-Gentlewoman and the Doctor of Physic do not stay the entire span of the play; they leave as soon as this brief scene comes to an end. Indeed Shakespeare's play Macbeth is unique for its use of asides and soliloquies in profusion, only indicating how characters are more than intent to keep their secret thoughts to themselves. Also, the so-called Unities of Time and Place have not been observed by the playwright. It is therefore only natural that there won't be any fixed choric entity to watch the entire course of the play from a neutral, detached standpoint. Also, unlike Sophocles' Theban commoners, the two minor characters in Macbeth are not allowed to speak with their royal mistress. Ironically, they are the extended audience in the sense that they cannot engage in any conversation with the 'Characters'. In both Oedipus the King and Macbeth, these choric characters have the fortune to peep into the royal affairs. The voyeuristic element, as already pointed out, cannot be dismissed in both cases. Yet, in the Shakespearean text it is not more than a sudden glimpse these two characters end up having, when they catch the royal lady off her guard. Unlike the royal spectators in both $A$ Midsummer Night's Dream and Hamlet, these two characters represent the lower spaces of the social hierarchy. They are only permitted to see and hear things, and interpret everything if they can; they cannot however break the 'wall' to communicate with the concerned character 'performing' within the performance. Once again, their incapacity to break through the 'wall' will remind the 'real' audience of their incapacity to act, although they are permitted to interpret things in their own way.

\section{Knowing and Not Knowing:}

At a certain level, the drama works on the oedipal dichotomy of 'knowing' and 'not knowing'. Lady Macbeth has been an Eve-like figure in the sense that she acts as a scapegoat to extenuate the sin of her male counterpart of having known what was forbidden. Of course, the Witches are women too, but they have been projected as anomalies of nature. Their capacity to look into the 'seeds of time' is what makes them powerful (for them at least, Foucault's powerknowledge equation seems well applicable). On the other hand Lady Macbeth, as the course of the play reveals, is ultimately revealed to be a 'feminine' character after all, filled with the milk of human kindness. The burden of the forbidden knowledge, combined with her utter rejection of her femininity, seems to wreak havoc on her mental stability. The words of the Doctor then carry 
an added meaning: "You have known what you should not." (Macbeth 273) In the ElizabethanJacobean context, this seems to reflect the Renaissance dictum (found in the Faustian dilemma too) that man's lust for knowledge/power must have a certain limit. Now, it is Lady Macbeth's knowledge of her involvement, both direct and indirect, in the black deeds of her husband that destabilizes her. But it is interesting to see that the same knowledge does not lead to any disastrous consequence when it is shared by the two 'common' observers. It is the 'knowing' of the community that determines the fate of the protagonists. The hatred of the collective, of the mass, has always exerted its power to topple even the most powerful rulers. In the Shakespearean scheme of the working of the Providence, it is Lady Macbeth (brilliantly described by Freud as the 'Other', or the darker Macbeth) who must fall before her male counterpart does. (Freud 309-333) Also, her innermost thoughts have been laid bare before the world. The 'exposed' lady, just like Titania, Desdemona and Cleopatra, must pay for been seen by all.

\section{The Female Discourse:}

It is interesting to see how the Waiting-Gentlewoman already 'knows' the nature of Lady Macbeth's sleep-walking. She has been present there all along, while the audience (in this case at least represented by the Doctor) were not. Paradoxical though it may sound, this is her familiarity with the 'pattern' embedded in 'chaos.' Is this because both are female? This allows one to bring in the dichotomy of the 'Symbolic' discourse and the 'Semiotic' one, as propagated by Julia Kristeva in her Desire in Language. From that perspective, the presence of the 'male' Doctor implies the imposition of the rational (or father's) discourse over the irrational (or mother's). The chaotic prose/verse of Lady Macbeth is a challenge to the firm linguistic pattern of the society. The 'spontaneous overflow' of female subconscious might threaten the fixed hierarchies and politics of the accepted language which is always 'male'. Hence the desperate attempt on the part of the Doctor of Physic to establish his confident prose/blank verse over the 'fluid', incoherent language of the 'infected' mind. They constantly interpret her apparently incoherent uttering, thereby finding 'truth' in what might otherwise be regarded as pure drivel. Also, the incapacity of the Doctor to cure his patient might be a reference to the inability of the male discourse to understand women in general.

It is following the Renaissance dichotomy regarding dreams that Lady Macbeth's words are to be regarded as both 'truthful' and 'dangerous'. A woman's unfiltered words, a somewhat Shakespearean version of ecriture feminine, must be censured at any cost. Hers is a story that runs parallel to her royal husband. But in the male-centric Shakespearean drama she is destined to find herself as a She-Devil. She has been absent since the Act III, Sc-iv, famously known as the Coronation Scene. Her transformation has then largely taken place off our sight, and the spectacle of the more vulnerable and feminine side of her self might appear to be shocking to the audience. Left alone by her husband, the Lady crumbles under the weight of her/their combined sense of guilt. Her 'confessions' are at hand, and someone has to be there at the receiver's end. The Waiting-Gentlewoman is already familiar with the tormented soul, but she does not want to be regarded as the only evidence, "having no witness to confirm [her] speech." (Macbeth 271) The 
Doctor of Physic, with his insufficient healing power, therefore becomes a somewhat ecclesiastical figure whose experiencing the penance-in-sleep-walking prepares the ground for Lady Macbeth's death. A nod to the Christian scheme of crime-penance-death, the fate of Lady Macbeth is therefore necessary for establishing the play as conforming to the moral-ethical-religious structure of the Elizabethan-Jacobean era. Whereas Macbeth's death on the battleground has a heroic quality adhered to it, it is the deglamorized, off-stage death (probably a suicide) of Lady Macbeth which better fits into the Shakespearean scheme of Providence.

\section{Interpreters and Amplifiers:}

The prospect of interpretation becomes really crucial in determining the role of these two 'minor' characters. Unlike Bottom (in A Midsummer Night's Dream), they engage the audience in the process of exegesis; or in other words, the 'translation' of the 'Semiotic' into the 'Symbolic'. For obvious dramatic reasons these two characters are necessary for 'amplifying' and carrying out Lady Macbeth's utterances to the audience. Indeed, for purely practical reasons, Lady Macbeth is not supposed to raise her voice to reach out to all the audience present in the theatre. This is not a soliloquy, and the mangled and incoherent utterances of this Lady must be channelized through some intermediary agency/-ies. It is therefore the purely technical requirement of the drama which necessitates the invention of these two minor characters. This act of 'amplification' is not beyond its due share of criticism though - the Waiting-Gentlewoman and the Doctor of Physic are not just simply carrying out the task of transmitting the received words to the audience verbatim, they are also adding their own sense of morality and judgement. Here is a small instance of Anagnorisis or revelation in which much of the endless rumours already in the air of Scotland do find a solid base. These two minor entities are no jury-judge-executioner, and yet their reactions will determine the overall acceptance or rejection of the larger community.

The Waiting-Gentlewoman and the Doctor of Physic, as already pointed out, have this remarkable capacity to communicate with these two worlds - the illusory world of enactment, and the 'real' world of the 'real' audience. Their lack of intention to interrupt the chaotic speech of Lady Macbeth quite naturally aligns them with the audience. They also determine the response of the audience. In this respect, they are standing on the borderline between the world of metaphors (although they are no more a part of it) and the world of interpretation. A brilliant study in metatheatre, they stretch the boundaries of the make-believe world and, surreptitiously, include the audience into the moral scheme of the play. They are and are not the audience at the same time. They 'watch', just as the 'real' audience do, but their watching brings about substantial changes in the course of the play. Now if the audience feel associated with these 'observers', they too find themselves as something more than just passive spectators. And this association, on the other hand, completes the process of 'alienation' of the audience from the murderers which was necessary to set the tone befitting the Act V. The Waiting-Gentlewoman with her 'knowledge' and the Doctor of Physic with his 'ignorance' complement each other; and after this scene they are on the same plain. 
The fact that the Doctor and the Gentlewoman are of different sexes cannot be a mere coincidence. In a way, their anticipation to watch the 'spectacle' of Lady Macbeth's somnambulism parallels that of Macbeth and Lady Macbeth as they enter and re-enter the bedchamber of Duncan in Act I, Sc-V (the doubling, or rather mirroring can also be traced perhaps coincidentally as one places Act I, Sc-V and Act V, Sc-i alongside each other). Duncan's dead body, at that point of time, represented a breach in nature, a source of chaos. Presently the sleep-walking appears as another anomaly in nature, as pointed out by the Doctor. (Macbeth 271) In the previous case, it was Lady Macbeth who seemed quite at ease (though only initially) with the prospect of murder, while Macbeth was visibly lacking in firmness of mind. Now too, it is the Gentlewoman who seems quite familiar with the 'pattern' of the 'chaos' that gets re-enacted almost in a ritualistic manner before the stunned 'male' gaze of the Doctor. This once again reminds one of the age-old tendencies of relating chaos, abnormalities and crime with womanhood. In a way, therefore, these two minor characters are doubling Macbeth and Lady Macbeth. Are they now representing the deep desire of the royal couple to unite, one more time, to reverse the course of time and go back to their prelapsarian stage? They had their bit of chance to remain passive onlookers and let events roll in their own accordance. They, instead, decided to topple the established design or order of the universe by becoming active participants, occupying the central stage. Consequently, their curse is unnatural too - separation from each other, inability to sleep, and ultimately losing their mental sanity in their respective ways.

\section{Distancing the Audience:}

During the murder of Duncan it was still necessary to retain the bond between the Macbeth-couple and the audience; hence the locus of crime remains off the stage all the time. This 'almost' experiencing the murder creates a sense of ambiguity; a lukewarm relationship between the audience and the central characters. In the sleep-walking scene, however, the two minor characters must have direct association with the audience; therefore the act of somnambulism takes place on the stage. This also contributes to the dissociation of the sane, rational (and predominantly 'male') world of the audience from the chaotic (and 'female') world of Lady Macbeth and her husband. An Alienation effect (or, the Verfremdungseffekt, to use the German term coined by Bertolt Brecht) is definitely the intended impact here, and it has been achieved with dexterity by the playwright. (Willet 91) To put it in plain words, the Alienation effect means "playing in such a way that the audience was hindered from simply identifying itself with the characters in the play. Acceptance or rejection of their actions and utterances was meant to take place on a conscious plane, instead of, as hitherto, in the audience's subconscious". (Wikipedia) Of course, no audience would like to be associated with the fate of the Lady who now seems all over the places both physically and psychologically. There can be a certain element of pity for this Lady who once appeared as the most dominant character around. But the logic of causality (even more obvious in the Elizabethan-Jacobean era) will make her appear not less than a She-Devil. The only solution that seems available to this aching mind, unable to sleep and still failing to fully wake up, seems death. After being alienated from her husband, she now gets alienated from the audience too. From the purely structural logic too, she must die now. This indicates the beginning of the 
Denouement; a journey restoring the balance of the universe by stripping the vicious of all their vices. The return to the rational world is further implied as the Gentlewoman too, by the end of the scene, seems to be on the same side as the Doctor.

\section{Conclusion}

It is therefore safe to conclude by saying that the Sleep Walking scene (Act V, Sc-i) of Macbeth deals with more issues than meet the eyes. Conventional criticism has always focused on the psyche of the Lady whose unconsciously drawled out words have been considered as a treasure trove for psychoanalytical studies. The present paper, however, considers the dramatic role of the two semi-silent, intermediary, 'amplifying' observers that have never been given their due importance in critical analyses of any age. This humble endeavour attempts to underscore the multiple dramatic, psychological and gender-based reasons behind this use of 'play-within-theplay' kind of trope with the hope of inspiring further researches.

\section{References}

Dutta, Sibaprasad. "The Sleepwalking Scene In Macbeth." researchgate.net. N.p., 2014. Web. 11 May 2021. <https://www.researchgate.net/publication/295546709_The_Sleepwalking_Scene_in_Macbeth>.

Freud, Sigmund et al. The Standard Edition of the Complete Psychological Works of Sigmund Freud. London: Vintage, 2001. Print.

Foucault, Michel. The History of Sexuality: The Will to Knowledge. New York: Pantheon Books, 1978. Print.

Kristeva, Julia, et al. Desire in Language: A Semiotic Approach to Literature and Art. Revised ed., New York: Columbia University Press, 1980. Print.

Seldan, Raman, Peter Widdowson, and Peter Brooker. A Reader's Guide to Contemporary Literary Theory. 5th ed. London: Pearson, 2005. Print.

Shakespeare, William, Ann Thompson and Neil Taylor. Hamlet. New Delhi: Bloomsbury, 2013. Print.

Shakespeare, William, Sandra Clark and Pamela Mason. Macbeth. New Delhi: Bloomsbury. 2015. Print.

Shakespeare, William, and W.J. Craig. Shakespeare: Complete Works. Delhi: Oxford University Press, 1978. Print.

Sophocles, and Robert Fagles. The Three Theban Plays. New York: Penguin, 1994. Print.

Willet, John. Brecht on Theatre. New York: Hill and Wang, 1964. Print.

"Distancing Effect - Wikipedia." En.wikipedia.org. N.p., 2021. Web. 11 May 2021. $<$ https://en.wikipedia.org/wiki/Distancing_effect>. 
Manidip Chakraborty is an Assistant Professor in the Department of English, Bhairab Ganguly College, WBSU. His interest areas include adaptation theory, psychoanalytical studies, and popular culture 